\title{
The Research of Polymer Film-Forming Plugging Agent for Drilling Fluid
}

\author{
Gang Liu, Chunzhi Luo, Baijing Wang \\ College of Chemistry and Environmental Engineering, Yangtze University, Jingzhou, China \\ Email: 13797350237@163.com
}

How to cite this paper: Liu, G., Luo, C.Z. and Wang, B.J. (2019) The Research of Polymer Film-Forming Plugging Agent for Drilling Fluid. Open Journal of Yangtze Gas and Oil, 4, 240-247.

https://doi.org/10.4236/ojogas.2019.44019

Received: April 28, 2019

Accepted: September 24, 2019

Published: September 27, 2019

Copyright $\odot 2019$ by author(s) and Scientific Research Publishing Inc. This work is licensed under the Creative Commons Attribution International License (CC BY 4.0).

http://creativecommons.org/licenses/by/4.0/

\begin{abstract}
In order to improve the plugging and anti-collapse performance of water-based drilling fluid, a polymer film-forming plugging agent LWFD is synthesized by emulsion polymerization. The effect of the agent on rheology, API filtration loss, lubricity and film plugging of polymer drilling fluid and cationic drilling fluid is evaluated in laboratory. The experimental results show that the agent has little effect on the rheology and filtration loss of polymer drilling fluid and cationic drilling fluid, and can improve the lubricity of drilling fluid. The synthesized polymer film-forming plugging agent LWFD has good plugging properties for sand discs with different permeabilities, and the agent can effectively improve the film-forming plugging and temperature resistance of drilling fluid when combined with the inorganic nano-plugging agent NMFD. The high performance polymer drilling fluid formed by introducing polymer film-forming plugging agent LWFD and inorganic nano-plugging agent NMFD into polymer drilling fluid has comparable performance as Halliburton's SHALEDRIL high performance drilling fluid, which can meet the requirements of on-site drilling and has application value.
\end{abstract}

\section{Keywords}

Film-Forming Plugging Agent, Emulsion Polymerization, Rheology, Lubrication Coefficient, Sand Disc Filtration Test

\section{Introduction}

When conventional water-based drilling fluids drill hard and brittle shale, the filtrate will invade the cracks and pore of shale, causing the hydration expansion and spalling of shale, drilling sticking, wellbore instability and other complex downhole situations are induced. Therefore, the oil-based drilling fluid system 
with strong inhibition, strong plugging and high lubricity is often utilized to exploit shale gas. However, oil-based drilling fluids cause serious environmental pollution and the subsequent treatment of cuttings is difficult, which limits their application. Therefore, Halliburton, Baker Hughes and other companies have developed high-performance water-based drilling fluid systems, which have been successfully applied in shale gas development in the United States, Saudi Arabia, Canada and China [1] [2]. The technology is to add one or several film-forming plugging agents to the water-based drilling fluid, so that the drilling fluid can form a semi-permeable membrane or separator on the surface of the shale, preventing the shale hydration expansion caused by the collapse of the wellbore [3] [4].

Film-forming plugging agents can be roughly classified into polymer film-forming plugging agents and inorganic nano-plugging agents. Inorganic nano-plugging agent can effectively block the narrow pores and cracks in the formation by utilizing its particle size advantage. However, when it is used alone, the formation adaptability is poor, and it will gradually aggregate and become larger in the aqueous solution and lose the blocking ability to the formation [5] [6]. Polymer film-forming plugging agent has excellent deformation and adsorption capability, which can preferentially adsorb pores and cracks on the surface of wellbore to form a polymer film. It has been reported both in the domestic and overseas [7] [8] [9] [10]. The key technology of foreign high performance drilling fluids is the successful application of polymer film-forming plugging agent, but its cost is not lower than that of oil-based drilling fluids with the high price of the polymer film-forming plugging agent. Therefore, it is necessary to study this kind of additives in order to reduce the cost of high performance water-based drilling fluids. Based on the idea of tunnel waterproofing, cement slurry reduction and wall waterproofing, some conventional monomers such as styrene, butadiene and acrylic acid are selected to synthesize a polymer film-forming plugging agent LWFD by emulsion polymerization. The polymer film-forming plugging agent LWFD is a polymer emulsion polymer with multiple adsorption groups, which can effectively block the pores and cracks of the formation and form a weakly crosslinked network structure on the surface of the wellbore to reduce the filtration loss of the drilling fluid. The effect of polymer film-forming plugging agent LWFD combined with inorganic nano-plugging agent NMFD is studied to improve the film-forming plugging property of drilling fluid.

\section{Development of Film-Forming Plugging Agent LWFD}

\subsection{Main Ingredients}

Styrene (St), butadiene (Bd), acrylic acid (AA), unsaturated fatty acid, octylphenol ethoxylate (OP-10), sodium dodecyl sulfate (SDS), sodium bicarbonate ( $\mathrm{NaH}$ $\mathrm{CO}_{3}$ ), ammonium persulfate (APS), all of the above reagents are of analytical grade. 


\subsection{Synthesis Method}

At room temperature, St, AA, unsaturated fatty acids, emulsifiers, buffers are added to the deionized water according to the formulation ratio, and stirred at a certain speed for 10 minutes on shear emulsion mixer to form stable white emulsion. Then, the white emulsion is transferred to a three-necked flask equipped with a reflux condenser, nitrogen is passed while stirring, and the white emulsion is heated to a predetermined temperature in water bath. The initiator APS is dissolved in deionized water to form aqueous initiator solution, and the Bd monomer is added while adding the initiator aqueous solution. The Bd monomer is added at one time after 30 minutes of reaction. After adding the initiator aqueous solution in 60 minutes, the stirring is continued for 4 hours to obtain the milky white liquid polymer film-forming plugging agent LWFD. The synthesized polymer film-forming plugging agent LWFD has a density of $0.95-1.03$ $\mathrm{g} / \mathrm{cm}^{3}$, a $\mathrm{pH}$ of $8-9$, and a viscosity of $50-55 \mathrm{mPa} \cdot \mathrm{s}$ at $25^{\circ} \mathrm{C}$.

\subsection{Infrared Spectra of LWFD}

As can be seen from Figure 1, $698.93 \mathrm{~cm}^{-1}$ and $759.38 \mathrm{~cm}^{-1}$ are the out-of-plane bending vibration peaks of $\mathrm{C}-\mathrm{H}$ in the benzene ring, $912.60 \mathrm{~cm}^{-1}$ and 968.19 $\mathrm{cm}^{-1}$ are the stretching vibration peaks of $\mathrm{C}=\mathrm{C}$ in butadiene, $1446.37 \mathrm{~cm}^{-1}$, $1493.30 \mathrm{~cm}^{-1}$ and $1601.21 \mathrm{~cm}^{-1}$ are the skeletal vibration peaks of the benzene ring, $1725.31 \mathrm{~cm}^{-1}$ is the stretching vibration peak of $\mathrm{C}=\mathrm{O}$ in acrylic acid and unsaturated fatty acid, $2848.17 \mathrm{~cm}^{-1}$ and $2920.41 \mathrm{~cm}^{-1}$ are the stretching vibration peaks of $\mathrm{C}-\mathrm{H}$ in saturated carbon chain, $3025.06 \mathrm{~cm}^{-1}$ is the stretching vibration peak of $\mathrm{C}-\mathrm{H}$ in unsaturated carbon chain. Infrared characterization results indicate that the styrene, butadiene, acrylic acid and unsaturated fatty acid monomers selected in the experiment are involved in the synthesis of the polymer film-forming plugging agent LWFD.

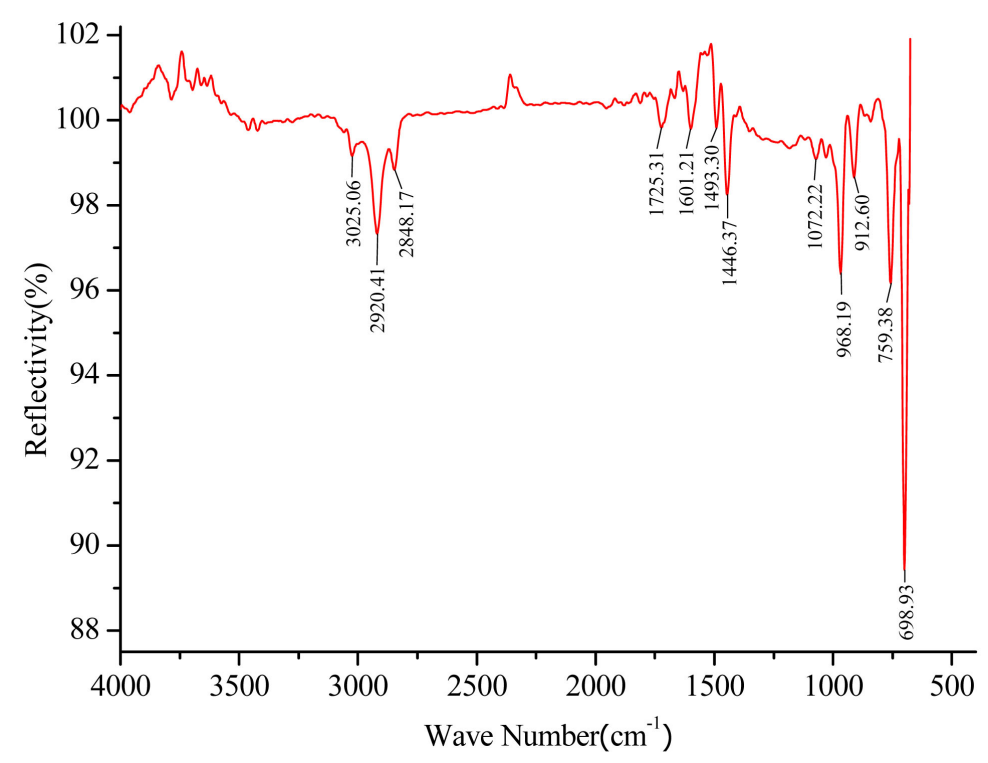

Figure 1. The infrared spectra of LWFD. 


\section{Performance Evaluation of LWFD}

\subsection{Impact on Conventional Water-Based Drilling Fluid Performance}

$2 \%$ polymer film-forming plugging agent LWFD is separately added to polymer drilling fluid and cationic water-based drilling fluid, and rolled it at $120^{\circ} \mathrm{C}$ for 16 h. The rheology, API filtration loss $\left(\mathrm{FL}_{\mathrm{API}}\right)$, lubrication coefficient $\left(\mathrm{K}_{\mathrm{f}}\right)$ of the two drilling fluids are measured for calculating lubricity improvement rate $\left(\mathrm{K}_{\mathrm{f}}^{\star}\right)$. The experimental results are shown in Table 1.

Table 1. The effects of LWFD on the performance of conventional water-based drilling fluid.

\begin{tabular}{ccccccc}
\hline Drilling fluid & AV/mPa.s & $\mathrm{PV} / \mathrm{mPa} \cdot \mathrm{s}$ & $\mathrm{YP} / \mathrm{Pa}$ & $\mathrm{FL}_{\mathrm{API}} / \mathrm{mL}$ & $\mathrm{K}_{\mathrm{f}} /$ & $\mathrm{K}_{\mathrm{f}}^{*} / \%$ \\
\hline 4\% Bentonite & 8.5 & 6.0 & 2.5 & 21.0 & 0.452 & - \\
4\% Bentonite + 2\% LWFD & 8.0 & 6.0 & 2.0 & 20.8 & 0.178 & 60.6 \\
Polymer Drilling Fluid & 31.5 & 23.5 & 8.0 & 5.1 & 0.132 & - \\
Polymer Drilling Fluid + 2\% LWFD & 30.5 & 21.5 & 9.0 & 4.9 & 0.090 & 31.8 \\
Cation Drilling Fluid & 35.5 & 25.0 & 10.5 & 5.6 & 0.145 & - \\
Cation Drilling Fluid + 2\% LWFD & 34.5 & 25.0 & 9.5 & 5.3 & 0.100 & 31.0 \\
\hline
\end{tabular}

The polymer drilling fluid formula: distilled water $+4 \%$ bentonite $+0.15 \%$ $\mathrm{HV}-\mathrm{CMC}+0.1 \% \mathrm{KPAM}+0.8 \% \mathrm{LV}-\mathrm{CMC}+0.6 \% \mathrm{LV}-\mathrm{PAC}, \rho=1.2 \mathrm{~g} / \mathrm{cm}^{3}$.

The cationic drilling fluid formula: distilled water $+4 \%$ bentonite $+0.2 \%$ $\mathrm{Na}_{2} \mathrm{CO}_{3}+0.2 \% \mathrm{NaOH}+0.5 \%$ cationic polymer $+0.5 \% \mathrm{LV}-\mathrm{CMC}+0.8 \%$ modified non-ionic starch $+3 \%$ non-ionic lubricant, $\rho=1.2 \mathrm{~g} / \mathrm{cm}^{3}$.

It can be seen from Table 1 , after adding $2 \%$ LWFD to the polymer drilling fluid and the cationic drilling fluid, the apparent viscosity, plastic viscosity, dynamic shear force and filtration of the drilling fluid decrease slightly, the lubrication coefficient decreases, and the lubricity increases by more than $30 \%$. It indicates that the polymer film-forming plugging agent LWFD has good compatibility with the drilling fluid, and it can also improve the lubricity of drilling fluid.

\subsection{Plugging Performance}

$2 \%$ polymer film-forming plugging agent LWFD is added to the polymer drilling fluid to form a plugging polymer drilling fluid, and rolled it at $120^{\circ} \mathrm{C}$ for $16 \mathrm{~h}$. Artificial sand discs with permeability of $400 \mathrm{mD}, 750 \mathrm{mD}$ and $2 \mathrm{D}$ are selected to measure the filtration loss of the drilling fluid at different times. The experimental results are shown in Figure 2.

As can be seen from Figure 2, the loss of sand disc filtration test of polymer drilling fluid with LWFD is much less than that of polymer drilling fluid without LWFD. The smaller the sand disc permeability is, the smaller the loss of sand disc filtration test is, which shows that LWFD has plugging ability for different permeability sand discs, and it is better for plugging low permeability sand discs. It indicates that LWFD has strong plugging adaptability for different pores and cracks in strata, it can prevent the shale hydration expansion and spalling caused by filtrate entering the shale, and keep the stability of wellbore. 


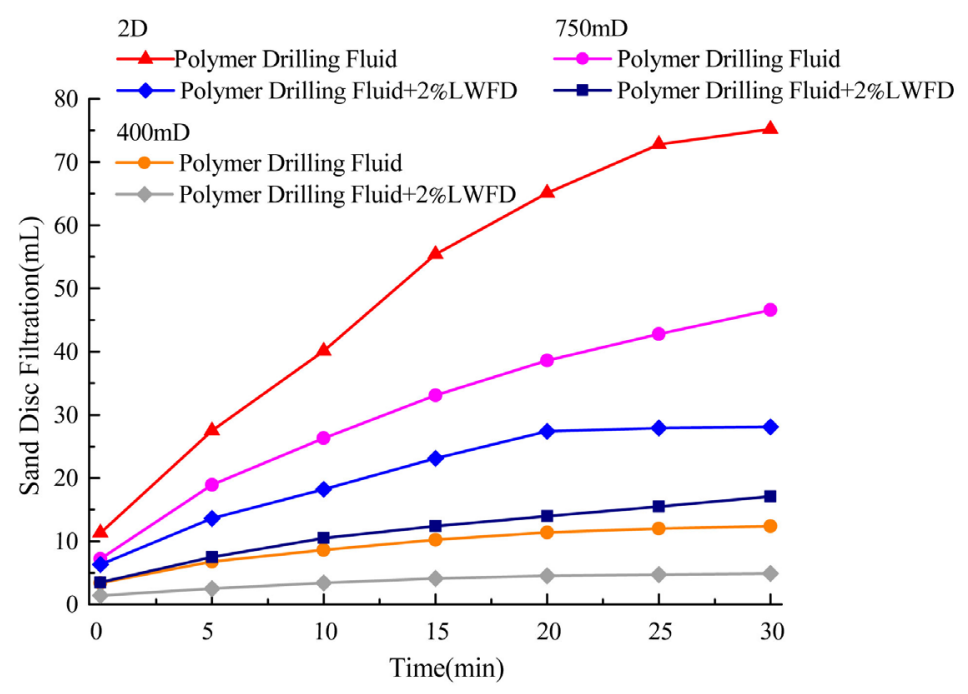

Figure 2. The plugging property of LWFD for sand discs with different permeabilities. Note: The experimental conditions of sand disc filtration test: $120^{\circ} \mathrm{C}, 3.5 \mathrm{MPa}, 30 \mathrm{~min}$.

\subsection{Synergistic Effect with Inorganic Nano-Plugging Agent NMFD}

Inorganic nano-plugging agent NMFD is a kind of nano-plugging material commonly used in drilling fluids. The main component of NMFD is $\mathrm{CaCO}_{3}$, which is inexpensive and works well in drilling fluid. In this study, the polymer film-forming plugging agent LWFD is compared with the inorganic nano-plugging agent NMFD to study the synergistic sealing effect between them at different temperatures. A compound plugging agent containing 2\% LWFD, 2\% NMFD, $2 \%$ LWFD and $2 \%$ NMFD is added to the polymer drilling fluid, and rolling it at different temperatures for $16 \mathrm{~h}$, a $750 \mathrm{mD}$ sand disc is select to measure the loss of sand disc filtration test of drilling fluid in 30 minutes. The experimental results are shown in Figure 3.

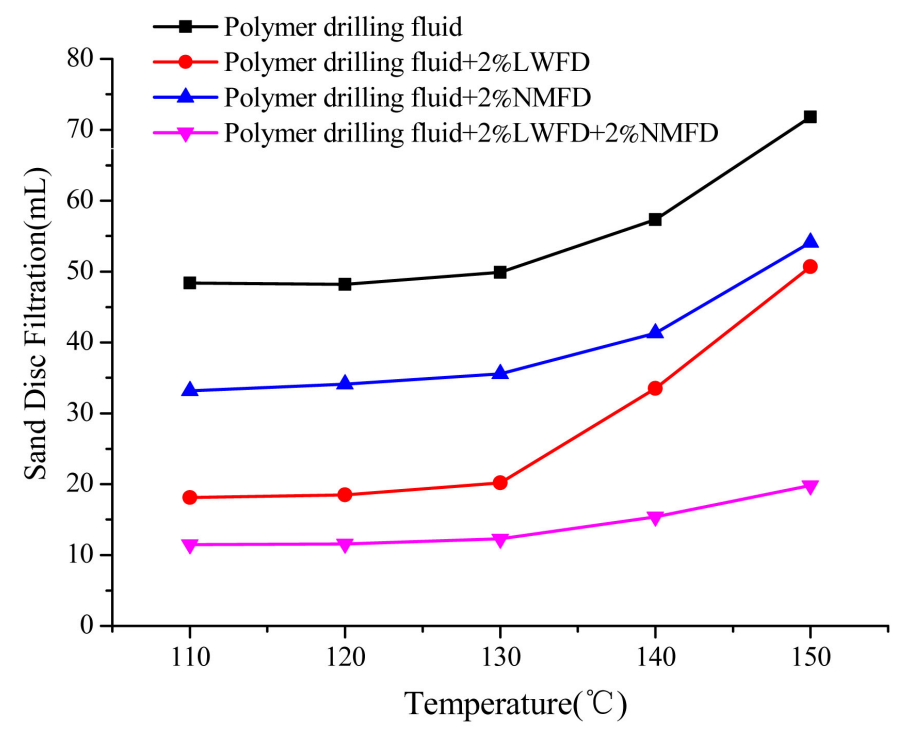

Figure 3. The synergistic effect of LWFD and NMFD at different temperatures. Note: The experimental conditions of sand disc filtration test: $120^{\circ} \mathrm{C}, 3.5 \mathrm{MPa}, 30 \mathrm{~min}$. 
As can be seen from Figure 3, after adding a film plugging agent to the polymer drilling fluid, the filtration loss of sand disc test of the drilling fluid will drop significantly. The filtration loss of sand disc test of the polymer drilling fluid with $2 \%$ LWFD is smaller than that of the polymer drilling fluid with $2 \%$ NMFD, indicating that the blocking ability of LWFD is stronger than that of NMFD. However, when LWFD and NMFD are added together to the polymer drilling fluid, the filtration loss of sand disc test of the drilling fluid is significantly less than that of the drilling fluid with one of the plugging agents, indicating that the combination of LWFD and NMFD can effectively improve the plugging performance of drilling fluids.

As the temperature increases, the polymer drilling fluid with plugging agent and the polymer drilling fluid without plugging agent have an increasing trend of sand disc filtration loss, but the sand disc filtration loss of the polymer drilling fluid compounded with LWFD and NMFD has a slow upward trend, indicating that the combination of LWFD and NMFD can effectively improve the temperature resistance of polymer drilling fluid system.

\section{Contrast with Foreign Products}

A high performance polymer drilling fluid is prepared by utilizing LWFD, NMFD and other conventional additives in laboratory, and rolling it at $130^{\circ} \mathrm{C}$ for $48 \mathrm{~h}$. The performances of the drilling fluid are measured and evaluated, which are compared with those of SHALEDRIL drilling fluid from Halliburton Company. The experimental results are shown in Table 2.

Table 2. The performance comparison of high performance polymer drilling fluid with SHALEDRIL from Halliburton.

\begin{tabular}{ccccccccc}
\hline Drilling fluid & $\mathrm{FV} / \mathrm{s}$ & $\mathrm{AV} / \mathrm{mPa} \cdot \mathrm{s}$ & $\mathrm{YP} / \mathrm{Pa}$ & $\mathrm{PV} / \mathrm{mPa} \cdot \mathrm{s}$ & $\mathrm{FL}_{\mathrm{API}} / \mathrm{mL}$ & $\mathrm{FL}_{\mathrm{HTHP}} / \mathrm{mL}$ & $\mathrm{K}_{\mathrm{f}}$ & $\mathrm{FL}_{\mathrm{PPT}} / \mathrm{mL}$ \\
\hline $\begin{array}{c}\text { high performance } \\
\text { polymer drilling fluid }\end{array}$ & 67 & 46.5 & 10.5 & 56.0 & 1.5 & 2.4 & 0.100 & 4.8 \\
$\begin{array}{c}\text { SHALEDRIL } \\
\text { SHALD }\end{array}$ & 65 & 45.5 & 11.5 & 51.0 & 1.1 & 1.9 & 0.085 & 3.5 \\
\hline
\end{tabular}

Note: The experimental conditions of HTHP filtration test: $110^{\circ} \mathrm{C}, 3.5 \mathrm{MPa}, 30 \mathrm{~min}$, and the experimental conditions of PPT filtration test: $750 \mathrm{mD}$, $130^{\circ} \mathrm{C}$ and $30 \mathrm{~min}$.

The high performance polymer drilling fluid formula: $1.2 \%$ bentonite $+0.5 \%$ soda $+0.8 \%$ composite multifunctional polymer $+0.8 \%$ viscosity reducer $+2.0 \%$ LWFD $+2.0 \%$ NMFD $+3.0 \%$ composite plugging agent $+2.0 \%$ polyamine inhibitor $+3.0 \%$ polyol $+3.0 \%$ lubricant, $\rho=1.47 \mathrm{~g} / \mathrm{cm}^{3}$.

As shown in Table 2, the rheological properties of the high performance polymer drilling fluid formed by introducing LWFD and NMFD into polymer drilling fluids are comparable to that of SHALEDRIL drilling fluids from Halliburton Company. The loss of API filtration test, HTHP filtration test and sand disc filtration test of the high performance polymer drilling fluid are slightly larger and lubricity is slightly worse, but the overall performance of the drilling fluid meets the requirements of on-site drilling and has application value. 


\section{Mechanism}

Polymer film forming plugging agent LWFD is a kind of emulsion polymer, which contains not only multiple adsorption groups, but also long carbon chain with oil affinity. The adsorbing group makes it firmly adsorb on the surface of shale, shale pore and fracture to form polymer film. The long carbon chain makes the surface of the film oil-affinity. Polymer membranes can effectively plug formation fractures and pores, prevent solid phase and free water from penetrating into the formation around the wellbore, so as to stabilize the wellbore and protect the reservoir. The oil-affinity of the membrane surface makes the lubricity of the membrane better, and further reduces the permeability of free water to the formation, thus further improving the stability of the formation and reservoir protection.

When the polymer film-forming plugging agent LWFD is combined with the inorganic nano-plugging agent NMFD, LWFD preferentially adsorbs in the pores and cracks on the surface of the wellbore by utilizing its excellent deformation and adsorption capacity, thereby forming a polymer film on the surface of the wellbore; the inorganic nano-plugging agent NMFD blocks the narrow pores on the polymer film and finally forms an isolation membrane on the surface of the wellbore. Even in the high temperature and high shear wellbore conditions, the degradation of the polymer film-forming plugging agent LWFD leads to increase mud cake pores formed by the drilling fluid, the inorganic nano-blocking agent NMFD can still block the pores of the mud cake and form a sealing film on the surface of the mud cake to improve the temperature resistance of the drilling fluid.

\section{Conclusions}

A polymer film-forming plugging agent LWFD is synthesized by emulsion polymerization utilizing styrene, butadiene, acrylic acid and unsaturated fatty acid as main materials, and the main performance of the polymer film-forming plugging agent LWFD is evaluated.

1) The polymer film-forming plugging agent LWFD has no effect on the rheology and the loss of API filtration test of conventional polymer drilling fluid and cationic drilling fluid, indicating that it has good compatibility in drilling fluid, and it can improve drilling fluid lubricity by more than $30 \%$.

2) The polymer film-forming plugging agent LWFD has good film-forming and plugging properties for sand discs with different permeabilities, indicating that LWFD has strong plugging adaptability for different pores and cracks in strata. When the polymer film-forming plugging agent LWFD is combined with the inorganic nano-plugging agent NMFD, it can further improve the drilling fluid blocking capacity and temperature resistance.

3) The high performance polymer drilling fluid formed by introducing LWFD and NMFD into polymer drilling fluid has comparable performance as Halliburton's SHALEDRIL high performance drilling fluid, which can meet the requirements of on-site drilling and has application value. 


\section{Foundation Project}

Project of National Natural Science Foundation of China "Research on Shale Wellbore Stability and Fracture Mechanism under Shale Gas Development Conditions" (51174036).

\section{Conflicts of Interest}

The authors declare no conflicts of interest regarding the publication of this paper.

\section{References}

[1] Deville, J.P., Fritz, B. and Jarrett, M. (2011) Development of Water-Based Drilling Fluids Customized for Shale Reservoirs. SPE International Symposium on Oilfield Chemistry, The Woodlands, 11-13 April 2011, SPE 140868. https://doi.org/10.2118/140868-MS

[2] Ramirez, M.A., Benaissa, S., Ragnes, G., et al. (2007) Aluminum Based HPWBM Successfully Replaces Oil-Based Mud to Drill Exploratory Well in the Magellan Strai, Argentina. SPE/ IADC Middle East Drilling and Technology Conference, Cairo, Egypt, 22-24 October 2007, SPE 108213. https://doi.org/10.2118/108213-MS

[3] He, M.M., Pu, X.L., Su, J.L., et al. (2010) Study on the Protection of Oil and Gas Layer in Water-Based Film-Forming Drilling Fluid. Drilling Technology, 33, 93-95.

[4] Dong, L.F., Chen, J.S., Jing, P., et al. (2018) Development and Application of Film-Forming Plugging Agent CMF for New Drilling Fluids. Drilling Fluids \& Completion Fluids, 35, 31-35.

[5] Mody, F.K., Tare, U.A. and Tan, C.P. (2002) Development of Novel Membrane Efficient Water-Based Drilling Fluids through Fundamental Understanding of Osmotic Membrane Generation in Shales. SPE Annual Technical Conference and EXhibition, San Antonio, Texas, 29 September-2 October 2002, SPE 77447. https://doi.org/10.2118/77447-MS

[6] An, Y.X., Jiang, G.C., Qi, Y.R., et al. (2015) Synthesis of Nano-Plugging Agent Based on AM/AMPS/NVP Terpolymer. Journal of Petroleum Science and Engineering, 135, 505-514. https://doi.org/10.1016/j.petrol.2015.10.014

[7] Yan, L.L., Li, C.J., Zhang, Z.L., et al. (2015) High Performance Water-Based Drilling Fluid Technology Based on Shale Gas "Water for Oil". Drilling Fluids \& Completion Fluids, 32, 1-6.

[8] Su, J.L., Chu, Q. and Ren, M. (2014) Properties of High Temperature Resistance and Salt Tolerance Drilling Fluids Incorporating Acrylamide/2-Acrylamido-2-Methyl-1Propane Sulfonic Acid/N-Vinylpyrrolidone/Dimethyl Diallyl Ammonium Chloride Quadripolymer as Fluid Loss Additives. Journal of Polymer Engineering, 34, 153-159. https://doi.org/10.1515/polyeng-2013-0270

[9] Zhao, Z.G., Pu, X.L., Xiao, L., et al. (2015) Synthesis and Properties of High Temperature Resistant and Salt Tolerant Filtrate Reducer N,N-Dimethylacrylamide 2-Acrylamido-2-Methyl-1-Propyl Dimethyl Diallyl Ammonium Chloride N-Vinylpyrrolidone Quadripolymer. Journal of Polymer Engineering, 35, 627-635. https://doi.org/10.1515/polyeng-2014-0260

[10] Jiang, G.C., Zhang, X.M., Dong, T.F., et al. (2018) A New Inhibitor of P(AMDMDAAC)/PVA Intermacromolecular Complex for Shale in Drilling Fluids. Journal of Applied Polymer Science, 135, 45584. https://doi.org/10.1002/app.45584 